\section{International Materials Research Congress to be Held in Cancun in August 2005}

The Academia Mexicana de Ciencia de Materiales, the International Union of Materials Research Societies, and the National Association of Corrosion Engineers, NACE International, Section Mexico, will hold the XIV International Materials Research Congress 2005, the 10th anniversary of the Materials World Network, and the IV NACE International Section Mexico meeting in Cancun, Mexico, August 21-25, 2005.

These annual meetings provide an interactive forum for discussing advances in synthesis, characterization, properties, processing, applications, basic research trends, and corrosion prevention related to the materials sciences area. The Materials World Network (MWN) is a global meeting place for all those interested in materials science, education, and technology. During the 10th anniversary celebration, conference attendees will be able to meet with global funding managers and learn about ongoing international research collaborations.

Along with 20 technical symposia, seven tutorials will be offered, and an equipment exhibition will feature products and services in the field of materials science and related topics. Symposia include Nanostructured Materials and Nanotechnology, Theory and Computer Simulation of Materials, Solar Cells and Solar Energy Materials, Magnetic Materials, Archaeological Issues in Materials Science, and Inter-American Collaboration in Materials.

The abstract deadline is May 15, 2005.

For more information, see Web site www.viep.buap.mx/ imrc2005.htm, or contact 29 Oriente. 601-1, Col. Ladrillera de Benítez, C.P. 72540, Puebla, Mexico; tel./fax 52-222-2114393 or 52222-2114394.
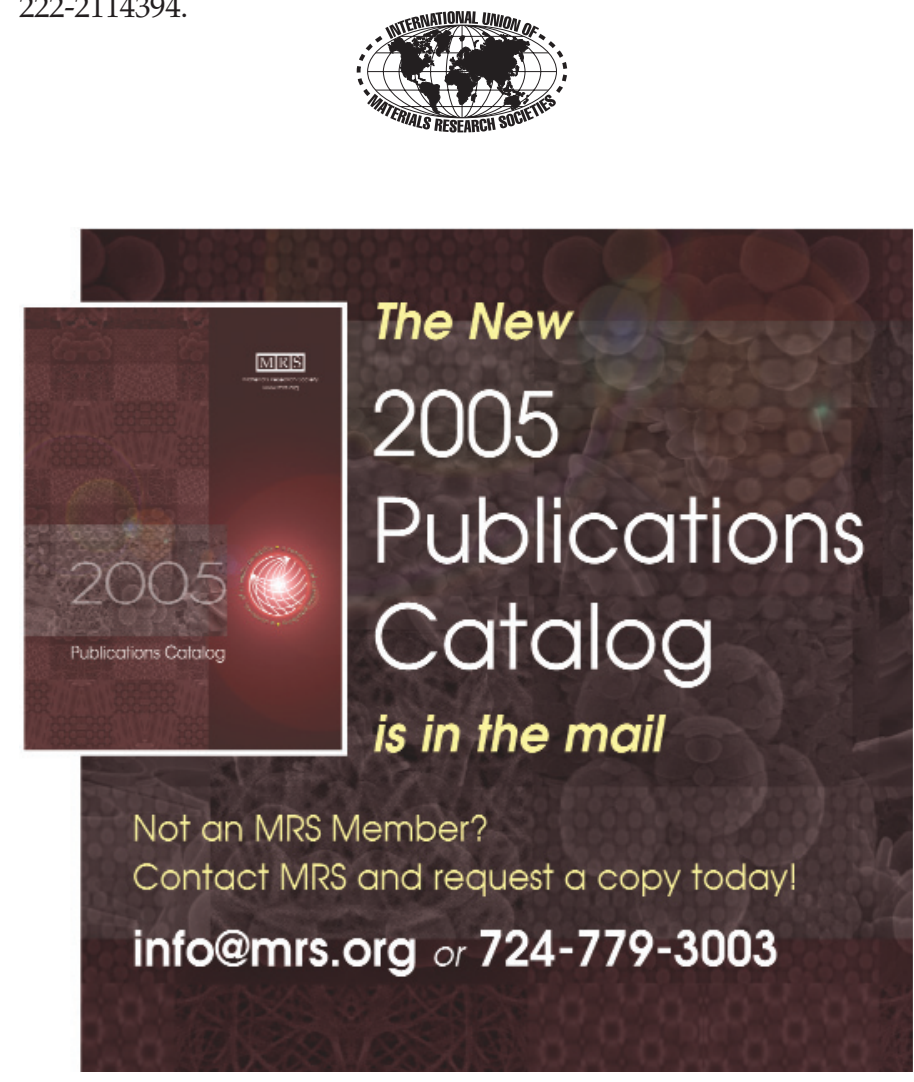
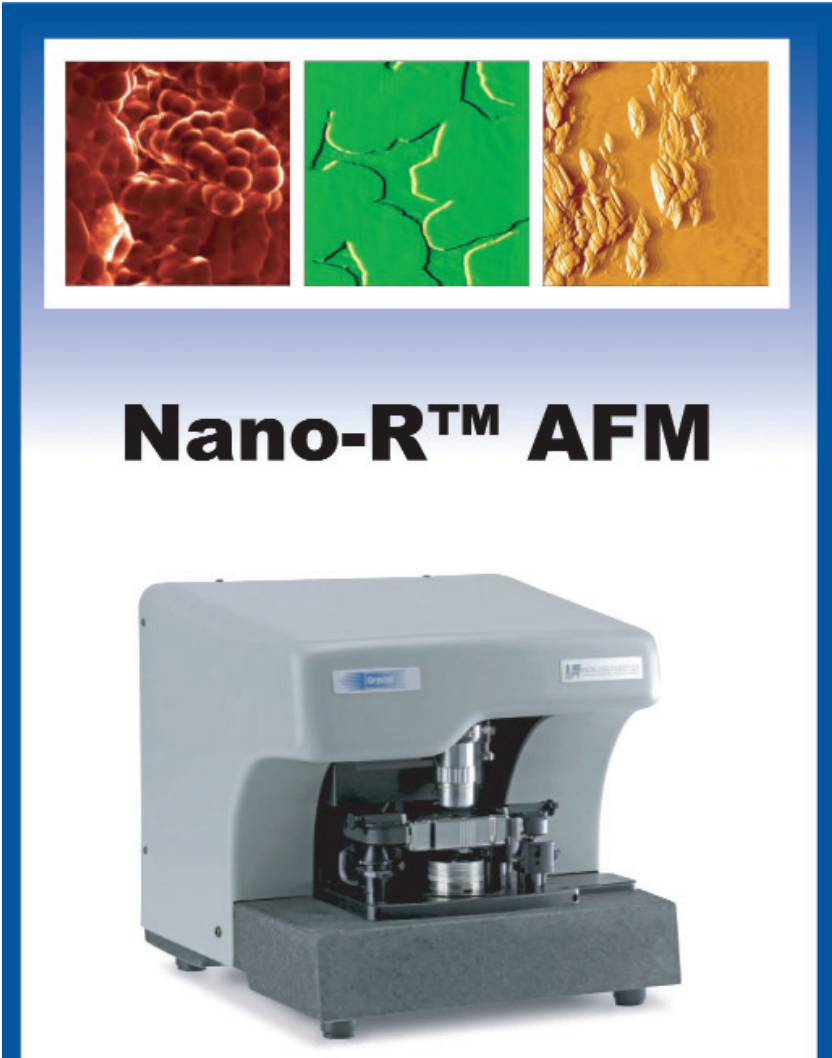

- High Performance

- Easy to Use

- Versatile

Nano- $R^{\mathrm{TM}}$ is available with a traditional light lever scanner and the advanced Crystal Scanner ${ }^{\mathrm{TM}}$.

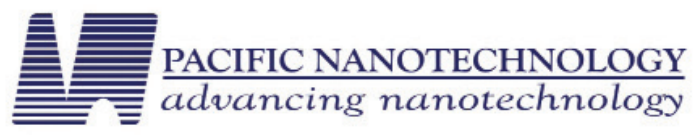

3350 Scott Blvd. \#29

Santa Clara, CA 95054

408-982-9492

www.pacificnanotech.com

www.probestore.com

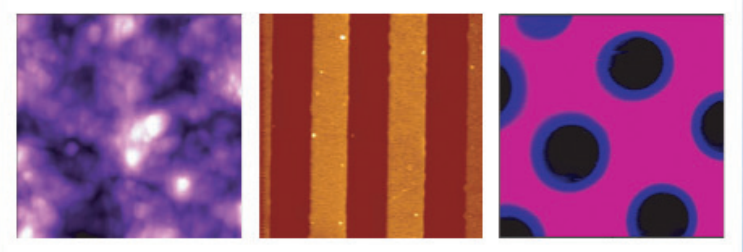

